\title{
Determinants of neoadjuvant chemotherapy use in muscle-invasive bladder cancer
}

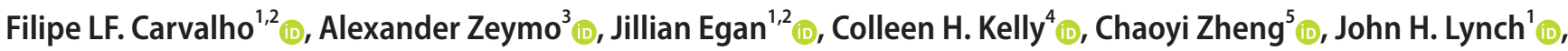 \\ Jonathan Hwang ${ }^{2}$ (i), Lambros Stamatakis ${ }^{2}$ (i), Ross E. Krasnow ${ }^{2}$ (i), Keith J. Kowalczyk ${ }^{1}$ (1) \\ 'Department of Urology, Medstar Georgetown University Hospital, Washington, DC, '2Department of Urology, Medstar Washington Hospital Center, Washington, DC, \\ ${ }^{3}$ MedStar Health Research Institute, Hyattsville, MD, ${ }^{4}$ School of Medicine, Georgetown University, Washington, DC, ${ }^{5}$ Department of Biostatistics, Bioinformatics, and \\ Biomathematics, Lombardi Comprehensive Cancer Center, Georgetown University, Washington, DC, USA
}

Purpose: Cisplatin-based neoadjuvant chemotherapy (NAC) followed by radical cystectomy (RC) is standard of care for muscleinvasive bladder cancer (MIBC). However, NAC is used in less than $20 \%$ of patients with MIBC. Our goal is to investigate factors that contribute to underutilization NAC to facilitate more routine incorporation into clinical practice.

Materials and Methods: We identified 5,915 patients diagnosed with CT2-T3NOMO MIBC who underwent RC between 2004 and 2014 from the National Cancer Database. Univariate and multivariable models were created to identify variables associated with NAC utilization.

Results: Only $18.8 \%$ of patients received NAC during the study period. On univariate analyses, NAC utilization was more likely at academic hospitals, US South and Midwest $(p<0.05)$. Higher Charlson score was associated with decrease use of NAC $(p<0.05)$. On multivariate analysis, treatment in academic hospitals (odds ratio [OR], 1.367; 95\% confidence interval [CI], 1.186-1.576), in the Midwest $(\mathrm{OR}, 1.538 ; 95 \% \mathrm{Cl}, 1.268-1.977)$ and South $(\mathrm{OR}, 1.424 ; 95 \% \mathrm{Cl}, 1.139-1.781)$ were independently associated with NAC utilization. Older age ( 75 to 84 years old; $\mathrm{OR}, 0.532 ; 95 \% \mathrm{Cl}, 0.427-0.664$ ) and higher Charlson score (OR, 0.607; $95 \% \mathrm{Cl}, 0.439-0.839$ ) were associated with decreased NAC utilization. Sixty-eight percent of patients did not receive NAC because it was not planned and only $2.5 \%$ of patients had contraindications for NAC treatment.

Conclusions: Our study demonstrates that NAC is underutilized. Decreased utilization of NAC was associated with older patients and higher Charlson score. This underutilization may be related to practice patterns as very few patients have true contraindications.

Keywords: Antineoplastic agents; Cystectomy; Urinary bladder neoplasms

This is an Open Access article distributed under the terms of the Creative Commons Attribution Non-Commercial License (http://creativecommons.org/licenses/by-nc/4.0) which permits unrestricted non-commercial use, distribution, and reproduction in any medium, provided the original work is properly cited.

\section{INTRODUCTION}

Bladder cancer is the 4th most common diagnosed cancer in American men leading to more than 12,000 cancer deaths in this year alone [1]. Roughly $25 \%$ of bladder cancer progresses to muscle-invasive bladder cancer (MIBC), which has a high rate of disease progression and recurrence due to micrometastatic disease [1-3]. Prior studies have shown that neoadjuvant chemotherapy followed by $\mathrm{RC}(\mathrm{NAC}+\mathrm{RC})$ significantly decreased incidence of lymph node metastases

Received: 21 September, 2019 • Accepted: 19 March, 2020

Corresponding Author: Filipe LF. Carvalho (iD https://orcid.org/0000-0003-2378-6512

Department of Urology, MedStar Georgetown University Hospital, 3800 Reservoir Rd NW, 1PHC, Washington, DC, USA

TEL: +1-202-444-4922, FAX: +1-202-444-7573, E-mail: filipe.decarvalho@gunet.georgetown.edu 
in T1-cT4 MIBC patients compared to those who received RC alone [2]. NAC is also associated with improvement in overall survival (OS), decreased recurrence rates and pathologic downstaging, without a significant increase in morbidity [46]. Since 2011, the National Comprehensive Cancer Network (NCCN) and the European Association of Urology (EAU) have endorsed cisplatin-based regimens $\mathrm{NAC}+\mathrm{RC}$ as the standard treatment for cT2-T4a node negative MIBC $[7,8]$.

However, despite these recommendations, utilization of NAC+RC remains as low as $11 \%$ to $20 \%$. Several factors, such as chemotherapy toxicity, provider fears that NAC delays definitive surgery, patient age, poor performance status, and a presumed lack of evidence to support the use of NAC followed by surgery may explain NAC underutilization [9,10]. Other reasons cited for not administering NAC were lack of medical oncologists for referral, socioeconomic and geographic factor, ethnicity, and insurance type [11]

Efforts have been made to properly identify patients best suited for NAC, as $56 \%$ to $70 \%$ of patients with MIBC are eligible for NAC [12]. Additionally, NAC utilization of NAC has been suggested to be a quality measure for bladder cancer treatment [13]. Our goal is to identify factors contributing to underutilization of NAC in order to better understand potential gaps in treatment and to guide further education on utilization of NAC in patients with MIBC.

\section{MATERIALS AND METHODS}

\section{Data source and study population}

The National Cancer Database (NCDB) is a joint cancer registry sponsored by the American College of Surgeons and the American Cancer Society that gathers clinical oncology data from more than 1,500 Commission on Canceraccredited facilities from the United States and Puerto Rico. NCDB captures more than $70 \%$ of newly diagnosed cancer cases nationwide and is an important source for quality improvement and cancer surveillance in the United States. Georgetown University Medical Center is a Commission on Cancer-accredited program. Bladder cancer NCDB data was requested and granted under application 2014.2396.

The NCDB participant user file from 2004 through 2014 contained 484,367 patients diagnosed with bladder cancer. We used the American Joint Committee on Cancer staging system to select those patients with clinically localized muscle-invasive disease (cT2NOM0 and cT3NOM0) to reflect appropriate patient selection for NAC utilizing NCCN, American Urological Association, and EAU guidelines. Only patients 18 years and older with NAC administered as first course of treatment followed by $\mathrm{RC}$ were consid- ered. Patients with history of other cancers, prior radiation, and those treated with hormone and immunotherapy were excluded. The study population was 5,915 patients, 1,113 received NAC followed by RC and 4,802 patients were treated with RC alone (Fig. 1).

\section{Variables and endpoints}

The primary goal of this study was to determine factors that influence NAC+RC utilization for MIBC. Covariates included patient age at diagnosis, gender, race (non-Hispanic white, non-Hispanic black, Hispanic or other), Charlson comorbidity index $(0,1,2)$, travel distance to medical provider, facility location (Northeast, South, Midwest, West), facility type (Community Cancer Program, Comprehensive Community Cancer Program, Academic/Research Program, Integrated Network Cancer Program), county type, education, type of insurance and county median income.

\section{Statistical analysis}

Unadjusted analysis using the chi-square and ANOVA tests were performed to investigate factors associated with NAC receipt. An adjusted analysis of NAC receipt was modeled using multivariable logistic regression to control for known confounders. Model building was based on hypothesis-driven inclusion criteria and a priori selection of control variables. Variables were categorized for easier interpretation. Referent categories were selected such that the reference was a natural null-state (i.e., Comorbidity score of 0 ; no insurance; low volume, non-academic referral) or the most common group (patient from a large metropolitan area; age between 65 to 74 ). All tests were two-sided, and p-values $<0.05$ were considered to be statistically significant. Data management and analysis was done in SAS 9.3 (SAS Institute, Cary NC, USA).

\section{RESULTS}

\section{Baseline characteristics}

Of all the 5,915 patients that fit our inclusion criteria, 1,113 (18.8\%) received NAC+RC and 4,802 (81.2\%) treated with $\mathrm{RC}$ alone.

Table 1 shows a detailed comparison of patient demographics and socioeconomic, geographic location, facility type, and clinical characteristics between NAC+RC and $\mathrm{RC}$ groups. Distribution of gender and race was similar between groups. On univariate analysis, $\mathrm{NAC}+\mathrm{RC}$ patients had Charlson score of zero, were more likely to be younger, treated at an academic center, treatment facility located in the US South and Midwest, had higher education and an- 


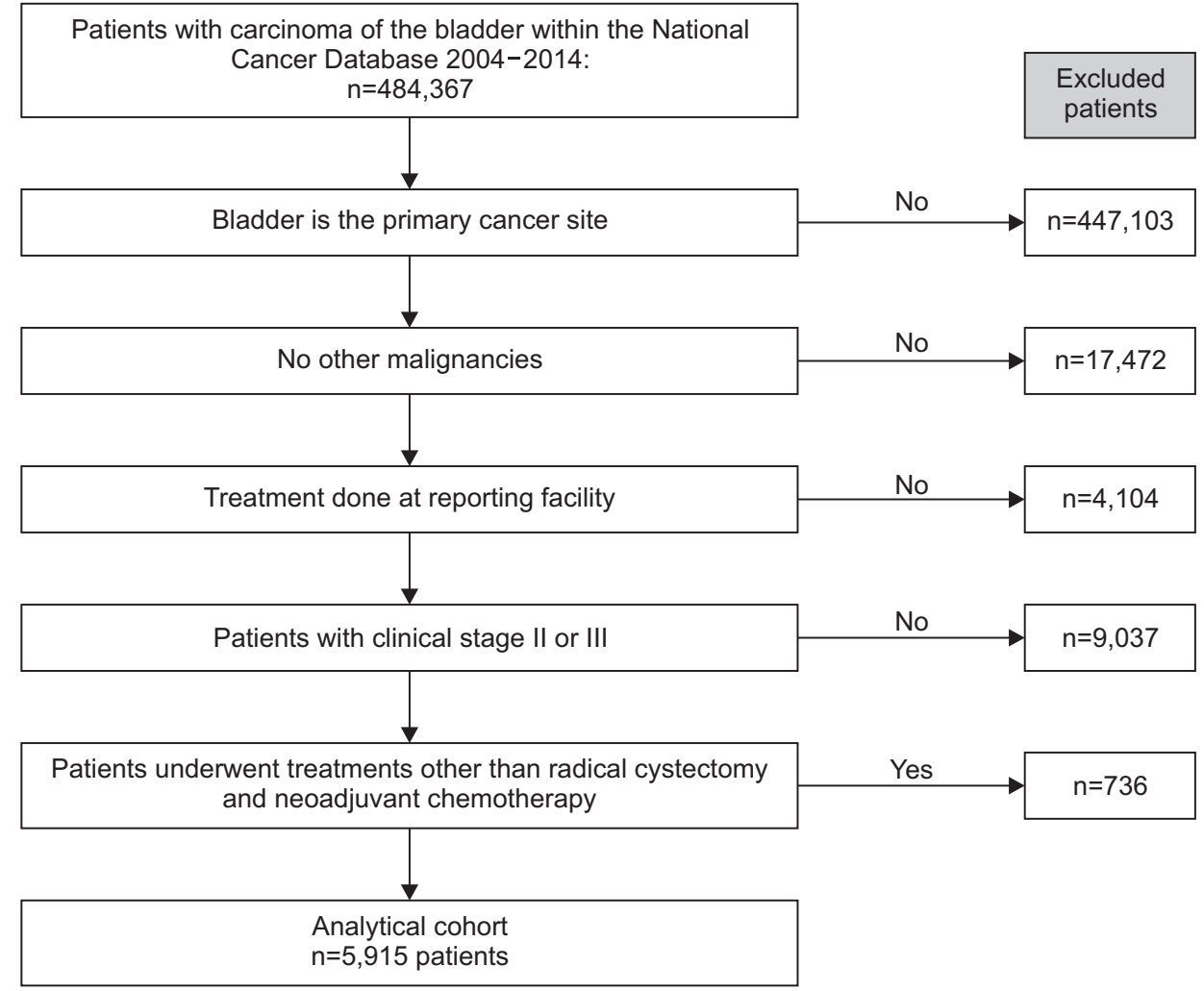

Fig. 1. Flowchart describing the selection of patient who underwent radical cystectomy with and without prior neoadjuvant chemotherapy for CT2NOMO and CT3NOMO bladder cancer. nual income $(\$ 48,000 \rightarrow \$ 63,000)$ compared with patients with $\mathrm{RC}$ alone (all p-values $<0.05$ ).

Multivariable logistic regression analysis to identify factors associated with receiving NAC prior to cystectomy is presented in Table 2. The odds of receiving NAC decreased significantly for patients older than 75 years old compared with patients aged 65 to 74 years (75 to 84 years odds ratio [OR], 0.532; 95\% confidence interval [CI], 0.427-0.664; $\geq 85$ years OR, 0.403; 95\% CI, 0.213-0.764) and in patients with Charlson score $\geq 2$ (OR, 0.607; 95\% CI, 0.439-0.839). Those treated at an academic center versus a Community or Integrated Network (OR, 1.367; 95\% CI, 1.186-1.576) were significantly more likely to be treated with NAC+RC. Rural location, education level and insurance were not independently associated with administration of NAC.

Table 3 demonstrates reasons given for not administering NAC prior to RC. According to NCDB variables, the most common reason for not receiving NAC was simply "not planned prior to surgery" (68.4\%). Only 2.5\% of patients did not receive NAC due to true contraindication and only $4.4 \%$ refused NAC when it was offered.

\section{DISCUSSION}

Our study has several important findings. First, our results show that NAC is vastly underutilized in the US with only $18.8 \%$ of patients receiving NAC+RC for MIBC when indicated, based on data from NCDB up until 2014. Patients with less comorbidities, treated in academic hospitals, in the US Midwest and South are more likely to be treated with NAC.

Several studies attribute the underutilization of NAC to patient co-morbidities, including cardiac dysfunction, renal failure, and advanced age [9,14]. Our results showed that patients older than 75 years old were in fact less likely to receive NAC (Table 2). However, of the $81.2 \%$ of patients who did not receive NAC, only $2.52 \%$ of patients were actually ineligible due to patient risk factors. In addition, 68\% of patients did not receive NAC simply because it was "not planned", implying that the option of receiving NAC+RC may not even be offered or discussed as a treatment option by some providers after the initial diagnosis of MIBC, which is alarming. These findings suggest there is an immense need for targeted intervention and education to increase the NAC utilization through multidisciplinary teams involving both urologists and medical oncologists. It is encouraging that in some studies encompassing data solely after initiation of the NCCN and EAU guidelines recommending NAC, a higher percentage of urologists discussing and utilizing NAC was noted compared to what has been previously reported [9].

Second, consistent with prior studies, our results did not 
Table 1. Analysis of patient demographic characteristics

\begin{tabular}{|c|c|c|c|c|}
\hline \multirow{2}{*}{ Characteristic } & \multicolumn{2}{|c|}{ Neoadjuvant chemotherapy } & \multirow{2}{*}{ OR } & \multirow{2}{*}{ p-value } \\
\hline & No & Yes & & \\
\hline Age (y) & $67(59-75)$ & $64(56-71)$ & 0.971 & $<0.001$ \\
\hline Travel distance & $13.9(5.5-39.2)$ & $14.5(6.1-39.8)$ & 0.999 & 0.560 \\
\hline \multicolumn{5}{|l|}{ Sex } \\
\hline Male & 85.23 & 84.52 & Ref. & \\
\hline Female & 14.77 & 15.48 & 1.062 & 0.51 \\
\hline \multicolumn{5}{|l|}{ Race } \\
\hline NH White & 82.63 & 83.53 & Ref. & \\
\hline NH Black & 5.01 & 5.25 & 1.040 & 0.793 \\
\hline Hispanic & 2.93 & 2.26 & 0.765 & 0.215 \\
\hline Other & 9.43 & 8.96 & 0.936 & 0.567 \\
\hline \multicolumn{5}{|l|}{ Charlson score } \\
\hline 0 & 68.60 & 74.57 & Ref. & \\
\hline 1 & 23.93 & 21.11 & 0.812 & 0.010 \\
\hline $2+$ & 7.48 & 4.31 & 0.531 & $<0.001$ \\
\hline \multicolumn{5}{|l|}{ Facility location } \\
\hline West & 18.21 & 14.03 & Ref. & \\
\hline South & 33.36 & 33.94 & 1.285 & 0.019 \\
\hline Midwest & 29.46 & 34.39 & 1.501 & $<0.001$ \\
\hline Northeast & 18.96 & 17.65 & 1.159 & 0.225 \\
\hline \multicolumn{5}{|l|}{ Facility type } \\
\hline Academic/research program & 44.15 & 53.37 & Ref. & \\
\hline Other & 55.85 & 46.63 & 0.691 & $<0.001$ \\
\hline \multicolumn{5}{|l|}{ Rurality } \\
\hline Metro & 75.41 & 76.28 & Ref. & \\
\hline Non-metro & 24.59 & 23.72 & 0.965 & 0.641 \\
\hline \multicolumn{5}{|l|}{ Percent No. high school degree } \\
\hline$>21 \%$ & 15.91 & 14.93 & Ref. & \\
\hline $13-20 \%$ & 25.38 & 24.8 & 1.041 & 0.714 \\
\hline $7-12.9 \%$ & 34.97 & 31.58 & 0.959 & 0.687 \\
\hline$<7 \%$ & 21.54 & 25.88 & 1.281 & 0.023 \\
\hline Unknown & 2.2 & 2.81 & 1.342 & 0.184 \\
\hline \multicolumn{5}{|l|}{ County median income } \\
\hline$<\$ 38,000$ & 16.7 & 14.3 & Ref. & \\
\hline$\$ 38,000-\$ 47,999$ & 26.47 & 23.44 & 1.048 & 0.668 \\
\hline$\$ 48,000-\$ 62,999$ & 26.49 & 29.59 & 1.316 & 0.010 \\
\hline$\geq \$ 63,000$ & 28.02 & 29.68 & 1.249 & 0.037 \\
\hline Unknown & 2.33 & 2.99 & 1.497 & 0.062 \\
\hline \multicolumn{5}{|l|}{ Insurance } \\
\hline No insurance & 3.67 & 3.68 & Ref. & \\
\hline Private & 35.42 & 44.74 & 1.257 & 0.206 \\
\hline Medicaid & 4.91 & 6.11 & 1.267 & 0.337 \\
\hline Medicare & 54.08 & 42.41 & 0.780 & 0.169 \\
\hline Other government & 0.81 & 1.53 & 1.871 & 0.064 \\
\hline Unknown & 1.10 & 1.53 & - & \\
\hline
\end{tabular}

Values are presented as median (interquartile range) or percentages only unless otherwise specified.

$\mathrm{OR}$, odds ratio; $\mathrm{NH}$, non-Hispanic.

show differences in NAC utilization based on race, gender or rurality [11]. However, we did demonstrate that treatment at academic hospitals and US geographic location were associ- ated with higher likelihood of NAC+RC. This may reflect a lapse in execution of newer treatment guidelines outside academic settings as well as providers' misinformed percep- 
Table 2. Multivariable analysis of covariates associated with receiving neoadjuvant chemotherapy

\begin{tabular}{|c|c|}
\hline Reasons for not receiving NAC & OR $(95 \% \mathrm{Cl})$ \\
\hline \multicolumn{2}{|l|}{ Age (y) (ref.=65-74) } \\
\hline $18-44$ & $1.536(0.906-2.604)$ \\
\hline $45-54$ & $1.127(0.868-1.463)$ \\
\hline $55-64$ & $1.177(0.943-1.470)$ \\
\hline $75-84$ & $0.532(0.427-0.664)$ \\
\hline$\geq 85$ & $0.403(0.213-0.764)$ \\
\hline \multicolumn{2}{|l|}{ Charlson score (ref. $=0$ ) } \\
\hline 1 & $0.875(0.736-1.039)$ \\
\hline$\geq 2$ & $0.607(0.439-0.839)$ \\
\hline \multicolumn{2}{|l|}{ Location of facility (ref.=West) } \\
\hline Midwest & $1.538(1.268-1.977)$ \\
\hline Northeast & $1.101(0.857-1.414)$ \\
\hline South & $1.424(1.139-1.781)$ \\
\hline \multicolumn{2}{|c|}{ Type of facility (ref.=Community or Integrated Network) } \\
\hline Academic/research program & $1.367(1.186-1.576)$ \\
\hline \multicolumn{2}{|l|}{ County-level income (lowest quartile) } \\
\hline 1st quartile (highest income) & $1.083(0.853-1.376)$ \\
\hline 2nd quartile & $1.426(1.106-1.839)$ \\
\hline 3rd quartile & $1.330(0.982-1.803)$ \\
\hline \multicolumn{2}{|l|}{ County-level education (lowest quartile) } \\
\hline 1st quartile (highest education) & $0.957(0.757-1.209)$ \\
\hline 2nd quartile & $0.859(0.668-1.104)$ \\
\hline 3rd quartile & $1.102(0.821-1.479)$ \\
\hline \multicolumn{2}{|c|}{ Rurality (ref.=metropolitan area $<1$ million) } \\
\hline Metro, 250,000-1 million population & $1.050(0.872-1.264)$ \\
\hline Metro, $<250,000$ population & $1.130(0.891-1.434)$ \\
\hline Non-metro, next to metro & $1.095(0.866-1.385)$ \\
\hline Non-metro, not next to metro & $0.887(0.640-1.230)$ \\
\hline \multicolumn{2}{|l|}{ Insurance (ref.=no Insurance) } \\
\hline Private & $1.277(0.881-1.849)$ \\
\hline Medicaid & $1.380(0.877-2.174)$ \\
\hline Medicare & $1.139(0.759-1.711)$ \\
\hline Other government & $1.648(0.799-3.395)$ \\
\hline
\end{tabular}

$\mathrm{NAC}$, neoadjuvant chemotherapy; $\mathrm{OR}$, odds ratio; $\mathrm{Cl}$, confidence interval.

tions that NAC is not effective in most patients or has sideeffects that delays RC. Rose et al. [15] showed that there truly may be significant delay to RC following NAC in the community setting, which may unfortunately reinforce perceptions that NAC delays definite treatment. Regarding side-effects from chemotherapy, large-scale analyses showed that toxicity and mortality from NAC is minimal [16,17] Our results support prior studies encouraging a multidisciplinary approach to improve communication between oncology and urology providers that increases NAC+RC utilization and improves time to treatment [18]. Additionally, it emphasizes the need for community outreach and education regarding best treatment practices for MIBC.

Third, we demonstrate increased utilization of NAC+RC in the US Midwest and South on univariable and multivariate analysis. This suggests that there may be persistent
Table 3. Reasons for not receiving neoadjuvant chemotherapy ( $\mathrm{n}=$ 4,802)

\begin{tabular}{lc}
\hline \multicolumn{1}{c}{ Covariates } & Number (\%) \\
\hline Not planned prior to cystectomy & $3,286(68.4)$ \\
Adjuvant chemotherapy & $1,016(21.2)$ \\
Contraindicated due to patient risk factors & $121(2.5)$ \\
Patient died prior to planned or recommended & $14(0.3)$ \\
chemotherapy & \\
Recommended, not administered & $213(4.4)$ \\
Unknown & $152(3.2)$ \\
\hline
\end{tabular}

geographic barriers to NAC administration, consistent with previous studies. This shows a concerning correlation between socioeconomic status and access to appropriate care for MIIBC which is seen for multiple diseases [19], and again reinforces need for community outreach and education, especially in underserved areas of the US. Multiple authors have reported that access to care and treatment disparities influence the outcomes of patients with MIBC. Bladder cancer mortality is associated with environmental and socioeconomic factors such as race, region and gender [20]. A recent study by Cole et al. [21] using a novel statistical modeling approach showed that eliminating disparities in access and treatment of MBIC results in essentially the same OS. These results have an enormous relevance for policy makers since it suggests that improving equity in access can reduce the impact of tumor characteristics in outcomes of patients with MIBC.

Our study has several limitations. First, our findings need to be interpreted within the limitations of the retrospective nature of the study and sampling bias of NCDB data up to 2014. In addition, NAC did not become part of the NCCN and EAU guidelines until 2011, which likely influenced practice patterns. This change may not be completely reflected in our results that encompass NCDB date from 2004 to 2014. To our knowledge, more recent data is not available, but would be important to investigate in the future. These results represent records from Commission on Cancer-approved hospitals and there may also be significant unmeasured confounders due to the limitations of the dataset. In addition, NCDB is a large population database and does not have granularity to assess preserved renal function which is requisite for cisplatin-based treatment, performance status, toxicity and time from chemotherapy to cystectomy. Finally, while population-based databases provide valuable information on a large-scale basis, subjects are not randomized and despite statistical matching of cohorts and controls on available variables, there may be other unknown confounding variables in these cohorts that cannot be controlled 
for.

\section{CONCLUSIONS}

In patients with MIBC, NAC is vastly underutilized mostly due to the failure of providers to offer it as an option in the initial treatment plan. Nonclinical factors such as geographic location and treatment at academic hospitals are associated with increased NAC utilization. Addressing discrepancies in patient access to care while advocating the implementation of guidelines across health care facilities may lead to an increase in the use of NAC and thus increase survival in patients with MIBC.

\section{CONFLICTS OF INTEREST}

The authors have nothing to disclose.

\section{AUTHORS' CONTRIBUTIONS}

Research conception and design: Filipe LF. Carvalho, Alexander Zeymo, and Keith J. Kowalczyk. Data acquisition: Filipe LF. Carvalho, Alexander Zeymo, Chaoyi Zheng, and Keith J. Kowalczyk. Statistical analysis: Filipe LF. Carvalho, Alexander Zeymo, Chaoyi Zheng, Ross E. Krasnow, and Keith J. Kowalczyk. Data analysis and interpretation: Filipe LF. Carvalho, Alexander Zeymo, Chaoyi Zheng, Ross E. Krasnow, and Keith J. Kowalczyk. Drafting of the manuscript: Filipe LF. Carvalho, Jillian Egan, Colleen H. Kelly, and Keith J. Kowalczyk. Critical revision of the manuscript: John H. Lynch, Jonathan Hwang, Lambros Stamatakis, and Ross E. Krasnow. Obtaining funding: Keith J. Kowalczyk and John H. Lynch. Administrative, technical, or material support: Filipe LF. Carvalho, Alexander Zeymo, Jillian Egan, and Colleen H. Kelly. Supervision: Filipe LF. Carvalho and Keith J. Kowalczyk. Approval of the final manuscript: Filipe LF. Carvalho, Alexander Zeymo, Jillian Egan, Colleen H. Kelly, Chaoyi Zheng, John H. Lynch, Jonathan Hwang, Lambros Stamatakis, Ross E. Krasnow, and Keith J. Kowalczyk.

\section{REFERENCES}

1. Siegel RL, Miller KD, Jemal A. Cancer Statistics, 2017. CA Cancer J Clin 2017;67:7-30.

2. Mertens LS, Fioole-Bruining A, Vegt E, Vogel WV, van Rhijn BW, Horenblas S. Impact of (18) F-fluorodeoxyglucose (FDG)positron-emission tomography/computed tomography (PET/ CT) on management of patients with carcinoma invading blad- der muscle. BJU Int 2013;112:729-34.

3. Wein AJ, Kavoussi LR, Partin AW, Peters CA. Campbellwalsh urology. 11th ed. Saint Louis: Elsevier Health Sciences; 2015;2184-204.

4. Grossman HB, Natale RB, Tangen CM, Speights VO, Vogelzang NJ, Trump DL, et al. Neoadjuvant chemotherapy plus cystectomy compared with cystectomy alone for locally advanced bladder cancer. N Engl J Med 2003;349:859-66.

5. Advanced Bladder Cancer (ABC) Meta-analysis Collaboration. Neoadjuvant chemotherapy in invasive bladder cancer: update of a systematic review and meta-analysis of individual patient data advanced bladder cancer (ABC) meta-analysis collaboration. Eur Urol 2005;48:202-5; discussion 205-6.

6. Kitamura H, Tsukamoto T, Shibata T, Masumori N, Fujimoto $\mathrm{H}$, Hirao Y, et al. Randomised phase III study of neoadjuvant chemotherapy with methotrexate, doxorubicin, vinblastine and cisplatin followed by radical cystectomy compared with radical cystectomy alone for muscle-invasive bladder cancer: Japan Clinical Oncology Group Study JCOG0209. Ann Oncol 2014;25:1192-8.

7. Clark PE, Spiess PE, Agarwal N, Bangs R, Boorjian SA, Buyyounouski MK, et al. NCCN Guidelines Insights: Bladder Cancer, Version 2.2016. J Natl Compr Canc Netw 2016;14:1213-24.

8. Stenzl A, Cowan NC, De Santis M, Kuczyk MA, Merseburger AS, Ribal MJ, et al. Treatment of muscle-invasive and metastatic bladder cancer: update of the EAU guidelines. Eur Urol 2011;59:1009-18.

9. Cowan NG, Chen Y, Downs TM, Bochner BH, Apolo AB, Porter MP, et al. Neoadjuvant chemotherapy use in bladder cancer: a survey of current practice and opinions. Adv Urol 2014;2014:746298.

10. Burger M, Mulders P, Witjes W. Use of neoadjuvant chemotherapy for muscle-invasive bladder cancer is low among major European centres: results of a feasibility questionnaire. Eur Urol 2012;61:1070-1.

11. Gandaglia G, Popa I, Abdollah F, Schiffmann J, Shariat SF, Briganti A, et al. The effect of neoadjuvant chemotherapy on perioperative outcomes in patients who have bladder cancer treated with radical cystectomy: a population-based study. Eur Urol 2014;66:561-8.

12. Vemana G, Nepple KG, Vetter J, Sandhu G, Strope SA. Defining the potential of neoadjuvant chemotherapy use as a quality indicator for bladder cancer care. J Urol 2014;192:43-9.

13. Cooperberg MR, Porter MP, Konety BR. Candidate quality of care indicators for localized bladder cancer. Urol Oncol 2009;27:435-42.

14. Zaid HB, Patel SG, Stimson CJ, Resnick MJ, Cookson MS, Barocas DA, et al. Trends in the utilization of neoadjuvant chemotherapy in muscle-invasive bladder cancer: results from the 


\section{Carvalho et al}

National Cancer Database. Urology 2014;83:75-80.

15. Rose TL, Deal AM, Basch E, Godley PA, Rathmell WK, Kim WY, et al. Neoadjuvant chemotherapy administration and time to cystectomy for muscle-invasive bladder cancer: an evaluation of transitions between academic and community settings. Urol Oncol 2015;33:386.e1-6.

16. Alva AS, Tallman CT, He C, Hussain MH, Hafez K, Montie JE, et al. Efficient delivery of radical cystectomy after neoadjuvant chemotherapy for muscle-invasive bladder cancer: a multidisciplinary approach. Cancer 2012;118:44-53.

17. Sternberg CN, Apolo AB. Everything old is new again! Neoadjuvant chemotherapy in the treatment of muscle-invasive bladder cancer. J Clin Oncol 2014;32:1868-70.

18. Walker M, Doiron RC, French SD, Brennan K, FeldmanStewart D, Siemens DR, et al. Peri-operative chemotherapy for bladder cancer: a survey of providers to determine barriers and enablers. Bladder Cancer 2018;4:49-65.

19. Galvin A, Delva F, Helmer C, Rainfray M, Bellera C, Rondeau V, et al. Sociodemographic, socioeconomic, and clinical determinants of survival in patients with cancer: a systematic review of the literature focused on the elderly. J Geriatr Oncol 2018;9:614.

20. Smith ND, Prasad SM, Patel AR, Weiner AB, Pariser JJ, Razmaria A, et al. Bladder cancer mortality in the United States: a geographic and temporal analysis of socioeconomic and environmental factors. J Urol 2016;195:290-6.

21. Cole AP, Fletcher SA, Berg S, Nabi J, Mahal BA, Sonpavde GP, et al. Impact of tumor, treatment, and access on outcomes in bladder cancer: can equal access overcome race-based differences in survival? Cancer 2019;125:1319-29. 